\title{
Spatial multicriteria analysis for sustainability assessment: A new model for decision making
}

\author{
Antonio Boggia $^{\mathrm{a}}$, Gianluca Massei ${ }^{\mathrm{a}}$, Elaine Pace ${ }^{\mathrm{b}}$, Lucia Rocchi ${ }^{\mathrm{a}, *}$, Luisa Paolotti ${ }^{\mathrm{a}}$, Maria Attard ${ }^{\mathrm{b}}$ \\ a Department of Agricultural, Food and Environmental Sciences - University of Perugia, Borgo XX Giugno, 74, 06121 Perugia, Italy \\ ${ }^{\mathrm{b}}$ Institute for Climate Change and Sustainable Development, OH132, University of Malta, Msida, Malta
}

\section{A R T I C L E I N F O}

\section{Keywords:}

Sustainable development

Sustainability assessment

Multi-criteria analysis

GIS

MCDA-GIS integration

\begin{abstract}
A B S T R A C T
Policy makers have to consider the sustainability perspective in strategic planning decisions. Identifyand measure the level of sustainability, through its three dimensions, is a priority. Therefore, the aim of this work is to present a new model, called GeoUmbriaSUIT, integrating Multicriteria Analysis and Geographic Information Systems, specifically developed for helping Decision Makers to take policy decisions about sustainability in planning. The model provides outputs which are easy to be understood by not experts; the evaluation path is traceable and transparent, thanks to back analysis.

To better explain the potentiality of GeoUmbriaSUIT and its functioning, a case study about Malta is described. Our results showed that in four regions of Malta the best dimension was the environmental one, while only for two regions (Northern Harbour and Southern Harbour) respectively the economic and social dimensions obtained the best scores. The integration of MCDA-GIS resulted to be a useful tool for sustainability assessment.
\end{abstract}

\section{Introduction}

Sustainable development is the guiding principle to address policies and development strategies at global level (Griggs et al., 2013). Every policy decision should be made taking into account not only the economic perspective, but at least also the social and environmental ones (Bohringer and Jochem, 2007). Despite the consideration of new dimensions of sustainability for example the institutional, cultural and technological ones, the main effort should be to identify, understand and measure first of all the economic, social and environmental dimensions (Sala et al., 2013). In addition to this, in the allocation of public funds for the development of human activities, decision makers should try to support those areas experiencing difficulties in achieving a balance between economic prosperity, social equity and environmental protection, and therefore requiring more urgent economic incentives to reach sustainability (UNCTAD, 2015).

In order to achieve these objectives, decision makers need adequate technical support, since the basis of good decision making rests on ex ante evaluation, in progress monitoring and ex post evaluation. However, sustainability assessment is one of the most complex types of appraisal methodologies (Sala et al., 2015).

Sustainability assessment can be developed using many different approaches, depending on the objectives, the scale and the scope (Cinelli et al., 2014). As a result, the literature on this topic is growing, offering a wide variety of different approaches (Bond et al., 2012). Some examples of models for sustainability assessment can be found in Boggia and Cortina (2010), who developed a methodological approach based on multi-criteria analysis to assess sustainability in specific areas, Kropp and Lein (2012) and Lombardi and Ferretti (2015), who produced aggregated indexes of sustainability, Lopez and Monzon (2010), who proposed a MCDSS working with three different indices, and the United Nations model called "dashboard of sustainability" (2015).

Waas et al. (2014) identified four different purposes of sustainability assessment in a decision-making strategy for sustainable development:

- Information generation for decision-making.

- Operationalization and forum for participation, debate and deliberation.

- Social learning.

- Structuring complexity.

Being a multi-dimensional concept, the assessment of sustainability is no longer based on a single indicator but on a set of indicators (Singh et al., 2012), which are mostly focused on economic, social and environmental measures (Pollesch and Dale, 2016). A basic requisite for a meaningful use of indicators and indices is the possibility to aggregate and make them comparable (Bohringer and Jochem, 2007). As a matter

\footnotetext{
* Corresponding author.

E-mail address: lucia.rocchi@unipg.it (L. Rocchi).
} 
of fact, the most appropriate tool for evaluating sustainability is a set of indicators, integrated in a tailored assessment methodology (). MultiCriteria Decision Analysis (MCDA) is one of them (Cinelli et al., 2014).

MCDA assumes a central role in the multi-dimensional evaluation process. It is used to solve complex problems by assessing all the variables, both individually and collectively, and assigning specific importance to each one (Cortina and Boggia, 2014). Thus, MCDA has been widely used to evaluate sustainability (Liu, 2007; Shmelev and LabajosRodrigues, 2009) and has been indicated as the appropriate tool for its assessment (Munda, 2005; Bond et al., 2012). One of the current research challenges in sustainability assessment is moving from multidisciplinarity towards transdisciplinarity via interdisciplinarity (Sala et al., 2013). MCDA is a typical transdisciplinary approach.

An important feature of sustainability assessment is its ability to provide decision makers with an evaluation of both global and local systems, considering short and long time reference periods, in order to determine actions to be implemented in a certain area (Ness et al., 2007). The practice of ranking countries can be a way to stimulate decision makers to improve their position (Dahl, 2012) and therefore their national levels of sustainability. However, the evaluation cannot be solely at a national level, although it is perhaps the most significant one (Dahl, 2012) and the most applied in international fora (Canavese et al., 2014). Systems at a local level must be investigated in order to have effective and realistic evaluations of specific territorial contexts, and to determine sound planning actions. Sustainable development is considered achievable if it originates on the local level; a bottom-up approach from local to supra-national (Ravetz, 2000). According to the European Union Policy, one of the most important drivers of sustainable development is the subsidiarity principle: the individual and the civil society must act freely, limiting the intervention of the institutions only when necessary. ${ }^{1}$ Accordingly, the interventions must be made to the institutional level closest to the people, with the widest possible participation.

Considering all these aspects, the aim of this work is to present our model for sustainability assessment at territorial level, called GeoUmbriaSUIT, which integrates the MCDA framework and Geographic Information Systems (GIS) (Massei et al., 2014). Spatial MCDA and the creation of a multi-criteria spatial decision support system (MCSDSS) combine the data management of GIS with the judgment capabilities of MCDA (Massei et al., 2014). A MCSDSS is part of the larger group of Spatial Decision Support Systems and it consists of three parts (Malczewski, 2010): a geographical component (database and management system), a MCDA model-based system and an interface. How much the MCDA and GIS parts are integrated and the presence of a unique interface determines the level of integration of the system. Several authors (Chakhar and Martel, 2003; Laskar, 2003; Chakahar and Mousseau, 2008; Massei et al., 2014,b; Ottomano Palmisano et al., 2016a,b) used a classification into three categories based on the level of integration: indirect, built-in and complete integration. However the only type of integration which allows to use the same database, interface and to access both the MCDA and GIS tools at any time during the analysis, is the complete one (Malczewski, 2010; Massei et al., 2014). More details on the theoretical ground of integration can be found in Chakhar and Martel (2003), Chakhar and Mousseau (2007) and Malczewski (2010).

Real life applications of MCDA-GIS integration have grown significantly in the last twenty years. Several authors focused on the usefulness of application in urban planning (Banai, 2005; Kropp and Lein, 2013; Lombardi and Ferretti, 2015), sustainable management and planning of forests (Sheppard, 2005; Store, 2009), catchment basins (Macleod et al., 2007; Prato and Herath, 2007; Kang and Lee, 2011) and ecological areas (White and Fennessy, 2005; Ferretti and Pomarico, 2013). However, examples of MCDA- GIS strategic sustainable planning

\footnotetext{
${ }^{1}$ Official Journal of the European Communities (OJ) C112, 20 December 1973, page 7.
}

applications are still rare (Banai, 2005; Ferretti and Pomarico, 2012; Lopez and Monzon, 2010; Manos et al., 2010; Ottomano Palmisano et al., 2016a,b). The present work describes a new integrated tool suitable for strategic and sustainable planning: GeoUmbriaSUIT. The case study where the model is applied is Malta, an island state in the middle of the Mediterranean Sea and the southernmost member of the European Union.

GeoUmbriaSUIT can be used at local, regional and national level, for comparing sustainability of different territorial areas. The three dimensions of sustainability are represented by means of a specific set of indicators. Currently, the model we proposed is the first MultiCriteria Spatial Decision Support System (MCSDSS), based on a complete integration of MCDA and GIS, especially developed for evaluating sustainability. As of July 2017, GeoUmbriaSUIT has been downloaded by several scholars and experts within the sector. In particular, the plugin has been installed 13,271 times in total. This has meant that over the last three years the model has been tested at international level on many occasions. It was presented at international conferences (Ottomano Palmisano et al., 2015; Paolotti et al., 2015; Rocchi et al., 2015; Boggia et al., 2016; Paolotti et al., 2016) and the first release of the version has already been applied to an Italian case study (Ottomano Palmisano et al., 2016a). The version presented here is the stable release.

The paper is structured as follows: after a description of the methodology used (Section 2) and of the case study (Section 3) results and discussions are presented in Section 4. The main conclusions to the study are presented in Section 5 of this paper.

\section{Methodology: the new model GeoUmbriaSUIT}

In this section we present our MCDA-GIS model, GeoUmbriaSUIT (http://plugins.qgis.org/plugins/), aimed to evaluate sustainability of certain areas at local, regional or national level using multiple criteria that cover environmental, economic and social aspects. We developed GeoUmbriaSUIT in 2014; it represents an evolution of the model UmbriaSUIT 1.0, ${ }^{2}$ developed by Boggia et al. (2007). GeoUmbriaSUIT consists of a plugin ${ }^{3}$ working in QuantumGIS (GIS Development Team, 2017), which is free and open-source GIS software, widely used in several fields and applications. The model allows for a complete MCDAGIS integration (Massei et al., 2014): it means, as explained above, that MCDA and GIS use the same interface and the same database. The MCDA approach is activated inside the GIS software exactly like any other analysis function.

Following is a brief description of the model. A complete manual of GeoUmbriaSUIT and a guide to installation are available at: http:// maplab.alwaysdata.net/geoUmbriaSUIT.html.

\footnotetext{
${ }^{2}$ UmbriaSUIT 1.0 is a monitoring tool of environmental and socio-economic aspects of a territory, for integrating the sustainability principle in local planning, developed in collaboration with Regional Environmental Protection Agency of Umbria (Italy). It was based on a weighted summation algorithm, calculated on two sets of indicators, environmental and socio-economic, obtaining an index of sustainability to compare different territorial areas.

${ }^{3}$ Among the many existing capabilities for geographic analysis, there is the possibility of developing tools for customization of the software, by creating plugins. The plugin is a not standalone program that interacts with another program to expand or extend its original functionality, allowing the use of new features not present in the main software. GeoUmbriaSUIT is basically a plugin, written in python language, which uses the library (set of functions or data structures) made available by the same QGIS to perform the processing requested by the user. In addition to perform the calculations provided by the algorithm evaluation, input and output data can be managed like any other geographic data and the user is free to operate additional geostatistical analysis, geoprocessing operations or reporting. It represents, in fact, the perfect integration of a multi-criteria analysis procedure with the geographical instrument. The type of data processed by the plug-in is the vector format.
} 


\subsection{Structure of the model}

GeoUmbriaSUIT is entirely developed in Python language, using the Application Programming Interfaces (APIs) of QGIS, in versions subsequent to 2.00. Specifically, the graphical interface is based on the "PyQT API", the same used for the QGIS graphical user interface, while the geographic processing modules use the "PyQGIS" interface. Graphic outputs (histograms and "bubble-graph") use the "Google charts" API (https://developers.google.com/chart/), directly accessed by Python to generate an html file, inside of which the synthesis graphs are inserted. The TOPSIS processing model is implemented in python and is part of the "pymcda" library - ver. 0.4, also available as a Python package (https://pypi.python.org/pypi/pymcda/0.4), which code is released under the GNU GPL License - ver. 2 (https://github.com/gmassei/ pymcda).

Also the implementation of the DOMLEM algorithm, for the analysis of results by means of the Dominance Based Rough Sets Approach (Greco et al., 2001a), is in Python, but its code is not yet available in the pymcda library and accompanies GeoUmbriaSUIT as a standalone module.

\subsection{Input description}

For the sustainability assessment the plugin GeoUmbriaSUIT uses a geographic vector file (e.g. a shapefile), where the graphic data represent the study area and the single evaluation units within it to be compared, i.e. the alternatives (e.g. the regions of a country if we are analyzing the whole national context, or the municipalities of a region if we consider a local context), while the alphanumeric data (attribute table), describe the environmental, economic and social aspects related to the evaluation units by means of a set of indicators (criteria).

In relation to the data requested for the functioning of the model, a limited input is required from the user (such as data associated to indicators, and with the weights needed for the weighting process). The interface provides for a set of subsequent screens, in which the user is guided in inserting data initially, and then in performing the multicriteria analysis. Examples of the different screens can be found within the manual.

\subsection{The multi-criteria algorithm used and indexes obtained}

The multi-criteria algorithm that we used within GeoUmbriaSUIT is the well-consolidated and widely applied TOPSIS (Technique for Order Preference by Similarity to Ideal Design) (Hwang and Yoon, 1981). This method is based on the concept that between all the possible solutions the one with the smallest distance from the best alternative and the highest distance from the worst has to be chosen. Actually, the algorithm defines a ranking based on the distance from the worst point and the closeness to an ideal point, for each of the criteria used. The main steps of the TOPSIS method are reported in the Appendix.

The plugin allows complete personalization. Unless otherwise indicated by the user, the highest value for each criterion becomes the ideal point, and the smallest the worst point, or vice versa, depending on whether the single indicator is considered a cost or gain. Entry of weights can be done directly, if known, or with the use of a pairwise comparison table, which is an optional step; in this way the user is led to define a final vector weight, by means of a repeatable and verifiable path, and the level of objectivity in the determination of the vector weights is increased.

In the implementation of GeoUmbriaSUIT, the use of the algorithm TOPSIS allows to treat individually the indicators representing each of the three dimensions of sustainability (environmental, economic, social), and to compute three different indices, for each geographic unit analyzed: Environmental Index (called EnvIdeal), Economic Index (EcoIdeal) and Social Index (SocIdeal).

Also an optional global index of sustainability can be obtained
(SustIdeal), by weighting the values of the three indices that compose it, through the intuitive use of sliding bars. However, using weighting summation to aggregate environmental, social and economic information in a sustainability index, as it is for SustIdeal, has some disadvantages, due to the method used (Rowley et al., 2012). Using weighting summation to produce aggregated indices has several limitations, in particular is the compensation effect which is generated between the environmental, social and economic aspects (Rowley et al., 2012). Therefore, indicators generated in this way are closer to the concept of weak sustainability. Indeed, at present the most accepted approach is that of strong sustainability which, according to many authors, is true sustainability (Ekins et al., 2003). This means keeping each component at a constant value with the material capital and the natural capital being not interchangeable.

\subsection{Output description}

The output of GeoUmbriaSUIT, which were directly projected, implemented and mainly incorporated within QGIS, are both alphanumeric and graphic. According to Monmonmier (1993) when work concerns the interaction among places, words with maps can be far more powerful as a vehicle for scholarly exposition than the same words without maps. The alphanumeric output is the values of the indices, already mentioned. The graphic output consists of maps, cartograms and graphs. The maps show the multi-criteria analysis results for each territorial unit analyzed, therefore the level of environmental, economic and social sustainability of the single alternatives. If choosing to apply the concept of weak sustainability, also a global sustainability map can be obtained, deriving from the weighting process of the three dimensions. The cartograms, instead, show a deformation of the areas investigated, depending on the intensity of the index and on the surface on which it is expressed. The higher the index, and the lower the actual area, the more the area will be distorted in excess, and vice versa.

In relation to the graphs, we implemented three different types of charts, i.e. the stacked (Bar of Sustainability) and flanked (Chart of Sustainability) histograms and the "bubble-graph". In the Bar of Sustainability, the overall height is proportional to the sustainability value of the three indices (EnviIdeal, EcoIdeal, SocIdeal). The three dimensions are added together and there is a global ranking for sustainability. However, the meaning of the Bar of Sustainability is not the same of SustIdeal. The stacked histogram is always produced by GeoUmbriaSUIT and it is always a simple overlapping of each dimension in a bar. SustIdeal is an optional index in which the three dimensions have to be weighted, given more importance to one or another, according to the decision maker's preferences on the relative importance of each one. In the sustainability histogram the three indices are reported one next to the other, without any compensation. The bubble-graph is a particular type of graph, in which the position and color of bubbles provide information about sustainability and its three dimensions. In particular, the $x$-axis is ordered according to the economic index, the $y$-axis is ordered according to the social index, the color (from red to green) is ordered according to the environmental index. Examples of the graphs that come out from the model are subsequently presented in the case study.

\subsection{Back analysis function}

In addition to the main path explained above, the plugin has the possibility to implement the DOMLEM algorithm (Greco et al., 2001b), based on the Dominance Based Rough Sets Approach (DRSA) (Greco et al., 2001a). In this case, the exemplary cases are the best alternatives found after the analysis. DRSA is not used to get ranking but to extract the decision rules that can explain the positions obtained by the alternatives in the ranking, based on the criteria used. Using it, transparency, traceability and back analysis capability are increased. Traceability means that from the final score it is possible to go back to the 


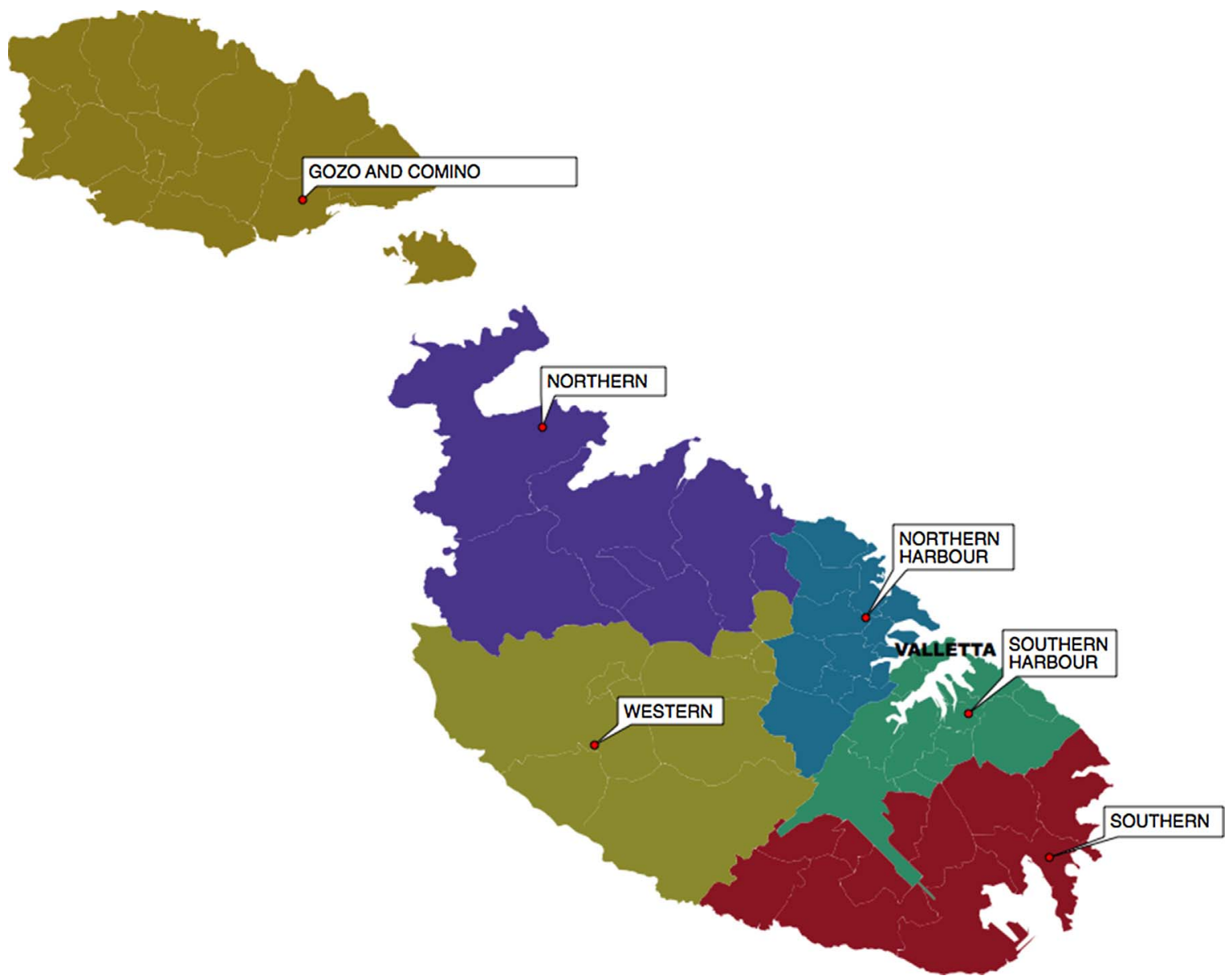

Fig. 1. The Regions of Malta.

rules and from the rules back to the input data. The back analysis is available only for the SustIdeal.

Ultimately, the main steps of the model GeoUmbriaSUIT can be summarized as follows:

1. Definition of a set of environmental indicators (ia1, ia2, ... ian), and entry of relative data.

2. Definition of a set of social indicators (is1, is2, ... isn), and entry of relative data.

3. Definition of a set of economic indicators (ie1, ie $2, \ldots$ ien), and entry of relative data.

4. Ranking of the alternatives using the TOPSIS algorithm (including weighing process) separately for the environmental, social and economic results and classification of the territory based on the achieved level of sustainability.

5. Rules extraction through DRSA, for the "back analysis".

\section{Study area and database}

Malta (Fig. 1) is one of the smallest states in the European Union and has one of the highest population densities in the world. With steady economic growth came unsustainable outcomes including increased environmental impacts which threaten the islands' quality of life and subsequently its economy (National Commission for Sustainable Development, 2006). The islands of Malta are characteristically Mediterranean however the influence of colonial powers over its history marks its culture and governance. Much of its regulations and administrative structures resemble that of Britain, under which Malta was a colony up until 1964. The British also influenced the relatively young planning system even though the Mediterranean setting and culture is evident throughout the islands' urban environment with old historical centers surrounded by recent urban growth within the islands' built-up areas. As a result, protected historical heritage sites lie adjacent to modern development resulting from post-war population growth, and to a certain extent lack of planning (Cilia, 1995).

The institutionalization of planning in the early $90 \mathrm{~s}$ allowed for the setting of limits to urban development and the protection of natural landscapes (Planning Services Division, 1992). The islands districts are therefore characteristic of either heavily urbanized areas with little or no open spaces whilst others enjoy rural and inevitably coastal environments.

The levels of sustainability in the islands of Malta are analyzed at a regional scale. All chosen indicators were collected for the six regions, which divide the islands. Table 1 details and describes the indicators used at regional level as they are divided into three types: environmental, economic and social. The selection of indicators was adapted from Pace (2014), which in turn was based on previous literature (e.g. Boggia and Cortina, 2010).

The data collection for all the indicators is reported in Tables 2-4. Using an effects table (first step in MCA) the impact of particular indicators on the regions was established and by applying standardization (second step), values were transformed into similar measurable units. In order to construct the weighting of each indicator (step three) local decision makers were asked to consider their region and rank the indicators in order of importance. A conventional 1 to 9 point scale (one being the least important and nine the most important) was used in a specific survey which was developed and sent to all the 68 local councils across the islands (Pace, 2014). Responses were received from $47 \%$ of the local decision makers. Using this data, quantitative weights for each indicator in every district was derived according to Saaty 
Table 1

Indicators meaning. The code before each indicator refers to the GeoUmbriaSuite code for Environmental (A), Social and Economic (E) Indicators.

\begin{tabular}{|c|c|c|}
\hline Indicator & Description & Source \\
\hline \multicolumn{3}{|l|}{ Environmental Indicators } \\
\hline A1-Air Pollution & $\begin{array}{l}\text { Measures the level of Nitrogen Dioxide }\left(\mathrm{NO}_{2}\right) \text {. One of the most common } \\
\text { pollutants in Malta caused by traffic, explosives and nearby volcanic activity. } \\
\text { It is associated with respiratory problems in the population which is well } \\
\text { documented in the islands population health (Montefort et al., 1997). }\end{array}$ & $\begin{array}{l}\text { Malta Environment and Planning Authority, (2014) } \\
\text { (superseded by the Environment and Resources } \\
\text { Authority-ERA www.era.org.mt) }\end{array}$ \\
\hline A2-Artificial Surface Area & $\begin{array}{l}\text { Represents the urbanized area of a region in relation to the total land area. } \\
\text { Pace (2014) used GIS to extract the information from the CORINE Land } \\
\text { Cover Map. }\end{array}$ & CORINE Land Cover Map (EEA, 2006) in Pace (2012) \\
\hline A3-Electricity Consumption per region & Electricity consumption per locality, aggregated to district for the year 2011. & Enemalta Corporation in Pace (2014) \\
\hline A4-Waste Separation & $\begin{array}{l}\text { Waste separation data for 2011. Data collected monthly and published in } \\
\text { metric tons. }\end{array}$ & Wasteserv Malta Limited in Pace (2014) \\
\hline A5-Water Consumption & $\begin{array}{l}\text { Water consumption based on survey data carried out by the National } \\
\text { Statistics Office in } 2011 .\end{array}$ & National Statistics Office (2011) in Pace (2014) \\
\hline A6-Ratio of people using public transport & $\begin{array}{l}\text { Over } 6,500 \text { households provided modal choice information in the } 2010 \\
\text { National Household Travel Survey. This indicator was calculated using this } \\
\text { survey for the whole of Malta. }\end{array}$ & Transport Malta (2010) in Pace (2014) \\
\hline \multicolumn{3}{|l|}{ Social Indicators } \\
\hline S1-Social Assistance total expenditure & Total government expenditure on social assistance for 2012 . & National Statistics Office (2013a) \\
\hline S2-Children allowance total expenditure & $\begin{array}{l}\text { Children Allowance a non-contributory benefit offered to families with } \\
\text { children. The data for this indicator was extracted for } 2012 \text {. }\end{array}$ & National Statistics Office (2013a) \\
\hline S3-Number of Women Unemployed & $\begin{array}{l}\text { Women's Unemployment Rate remains high in the islands. The data for this } \\
\text { indicator was extracted from the } 2011 \text { Census of Population. }\end{array}$ & National Statistics Office (2012) \\
\hline S4-Work Related Accidents & The data for this indicator was extracted from the 2011 Census of Population. & National Statistics Office (2012) \\
\hline S5-Higher Education & $\begin{array}{l}\text { Malta's participation in higher education is still below the national and } \\
\text { European targets. The data for this indicator was extracted from the } 2011 \\
\text { Census of Population. }\end{array}$ & National Statistics Office (2012) \\
\hline \multicolumn{2}{|l|}{ Economic Indicators } & National Statistics Office (2012) \\
\hline E1-Population Density & $\begin{array}{l}\text { Regional density represents the density of people living over a district and is } \\
\text { adequate for national level analysis. The data for this indicator was extracted } \\
\text { from the } 2011 \text { Census of Population. }\end{array}$ & National Statistics Office (2012) \\
\hline E2-Unemployment Rate & $\begin{array}{l}\text { Malta has the fourth lowest rate of unemployment in the European Union. } \\
\text { The data for this indicator was retrieved from the } 2011 \text { Census of Population. }\end{array}$ & National Statistics Office (2012) \\
\hline E3-Household Disposable Income & $\begin{array}{l}\text { Information on Household Disposable Income by district was obtained from } \\
\text { the } 2012 \text { Maltese Survey of Income and Living Conditions (SILC). }\end{array}$ & National Statistics Office (2013b) \\
\hline E4-Number of Tourist Establishments & $\begin{array}{l}\text { Tourism establishments are an important sustainability indicator, since the } \\
\text { economy of the Maltese Islands depends largely on the income brought about } \\
\text { by tourism. The data for this indicator was collected from the Malta Tourism } \\
\text { Authority in } 2012 \text {. }\end{array}$ & Malta Tourism Authority (2014) \\
\hline E5-Number of Registered Companies & $\begin{array}{l}\text { The data for the number of registered companies per district was obtained } \\
\text { from Registry of Companies at the Malta Financial Services Authority in } \\
2012 \text {. }\end{array}$ & MFSA (2014) \\
\hline E6-People at Risk of Poverty & $\begin{array}{l}\text { The number of people at risk of poverty was obtained from the National } \\
\text { Statistics Office from a data collection exercise carried out in } 2011 \text {. }\end{array}$ & National Statistics Office (2013b) \\
\hline
\end{tabular}

(1987). Table 5 reports the results of such a process and specifies if each indicator is considered a cost or a gain, according to the scope of analysis. If an indicator is considered a cost, higher values indicate worse performance. If it is considered a gain higher values indicate best performance.

\section{Results and discussion}

The environmental, social and economic indicators and weights for Malta's six regions were inputted in the GeoUmbriaSUIT. The outputs produced were alphanumeric and graphic and they present, in a geographical way, the rank provide by the TOPSIS method. Table 6 provides the values for the EnvIdeal, EcoIdeal and SocIdeal. Figs. 2-5 represent the geographical outputs related to each index and to the global sustainability evaluation (SustIdeal). The classification of alternatives is on a 5-classes scale, from very low to very high, for each dimension. The definition of the range for each class is based on a QGIS function, the equal interval algorithm. Maps give a quick and easy understanding of the geographic distribution of the indices, according to the chosen territorial level.

Table 2

Environmental Indicators: data collected.

\begin{tabular}{|c|c|c|c|c|c|c|c|}
\hline \multirow[t]{2}{*}{ Environmental Indicators } & \multirow[t]{2}{*}{ u.m. } & \multicolumn{6}{|l|}{ Malta Regions } \\
\hline & & Gozo and Comino & Northern & Northern Harbour & South Eastern & Southern Harbour & Western \\
\hline A1-Air Pollution $\left(\mathrm{NO}_{2}\right)$ & Moles & 195.08 & 281.65 & 507.99 & 284.39 & 435.27 & 300.18 \\
\hline A2-Artificial Surface Area & $\mathrm{Km}^{2}$ & 653.51 & 1069.26 & 5858.04 & 1230.66 & 5186.03 & 1895.13 \\
\hline A3-Electricity Consumption per region & $\mathrm{kWh}$ & 5273874 & 22800212 & 34446663 & 27265654 & 23817250 & 12908666 \\
\hline A4-Waste Separation & $\%$ & 20.77 & 13.97 & 13.37 & 17.87 & 23.11 & 14.29 \\
\hline A5-Water Consumption per capita per year & 1 & 11667 & 3641 & 8071 & 4933 & 6990 & 6306 \\
\hline A6-Ratio of people using public transport & $\%$ & 8.41 & 5.04 & 4.88 & 4.02 & 3.58 & 5.76 \\
\hline
\end{tabular}


Table 3

Social Indicators: data collected.

\begin{tabular}{|c|c|c|c|c|c|c|c|}
\hline \multirow[t]{2}{*}{ Social Indicators } & \multirow[t]{2}{*}{ u.m. } & \multicolumn{6}{|l|}{ Malta Regions } \\
\hline & & Gozo and Comino & Northern & Northern Harbour & South Eastern & Southern Harbour & Western \\
\hline S1-Social Assistance total expenditure & Euros & 1413 & 4670 & 10283 & 4718 & 9833 & 2725 \\
\hline S2-Children allowance total expenditure & Euros & 1833 & 4120 & 7719 & 4327 & 6984 & 3010 \\
\hline S3-Women Unemployed & n. & 367 & 648 & 1281 & 832 & 898 & 418 \\
\hline S4-Work Related Accidents & n. & 7.6 & 50.5 & 113.7 & 57.5 & 135.8 & 34.9 \\
\hline S5-Higher Education & $\%$ & 28 & 36 & 33 & 28 & 21 & 35 \\
\hline S6-Demographic Dependency Ratio & $\%$ & 49.3 & 41.5 & 46.5 & 41.3 & 49.63 & 43.4 \\
\hline
\end{tabular}

Table 4

Economic Indicators: data collected.

\begin{tabular}{|c|c|c|c|c|c|c|c|}
\hline \multirow[t]{2}{*}{ Economic Indicators } & \multirow[t]{2}{*}{ u.m. } & \multicolumn{6}{|l|}{ Malta Regions } \\
\hline & & Gozo and Comino & Northern & Northern Harbour & South Eastern & Southern Harbour & Western \\
\hline E1-Population Density & people per km2 & 454 & 863 & 4997 & 1278 & 3026 & 799 \\
\hline E2-Unemployed & n. & 985 & 1532 & 3509 & 2925 & 3089 & 1188 \\
\hline E3-Household Disposable Income & '000 Euros per Inhabitants & 220.23 & 470.953 & 950.878 & 462.864 & 545.399 & 476.694 \\
\hline E4-Number of Tourist Establishments & n. & 11 & 33 & 70 & 7 & 5 & 4 \\
\hline E5-Number of Registered Companies & $\mathrm{n}$. & 1027 & 2309 & 33304 & 1489 & 17797 & 1693 \\
\hline E6-People at Risk of Poverty & n. & 4610 & 9020 & 17770 & 8740 & 13250 & 8140 \\
\hline
\end{tabular}

Table 5

Weighting.

\begin{tabular}{|c|c|c|c|c|c|}
\hline Environmental Indicators & Weights $^{\mathrm{a}}$ & Social Indicators & Weights $^{\mathrm{a}}$ & Economic Indicators & Weights $^{\mathrm{a}}$ \\
\hline A1-Air Pollution $\left(\mathrm{NO}_{2}\right)$ & 0.253 (Cost) & S1- Social Assistance total expenditure & 0.2 (Gain) & E1- Population Density & 0.25 (Cost) \\
\hline A2-Artificial Surface Area & 0.115 (Cost) & S2- Children allowance total expenditure & 0.013 (Gain) & E2- Unemployed & 0.187 (Cost) \\
\hline A3-Electricity Consumption per region & 0.184 (Cost) & S3- Women Unemployed & 0.26 (Cost) & E3- Household Disposable Income & 0.125 (Gain) \\
\hline A4-Waste Separation & 0.218 (Gain) & S4- Work Related Accidents & 0.2 (Cost) & E4- Number of Tourist Establishments & 0.25 (Gain) \\
\hline A5-Water Consumption per capita per year & 0.0805 (Cost) & S5-Higher Education & 0.26 (Gain) & E5- Number of Registered Companies & 0.187 (Gain) \\
\hline A6-Ratio of people using public transport & 0.149 (Gain) & S6- Demographic Dependence Ratio & 0.067 (Cost) & E6- People at Risk of Poverty & 0.001 (Cost) \\
\hline
\end{tabular}

a Cost and Gain under the weight indicate if the related criteria has to be considered as a cost (the lower the value, the better the evaluation) or a gain (the higher the value, the better the evaluation).

Fig. 2 shows the classification of Malta's regions according to the environmental dimension (EnvIdeal). The most representative class is the Medium, with three regions. Only one region belongs to the very high class (Gozo and Comino) and another one (Northern Harbour) belongs to the very low class. Considering the economic indices the situation is different (Fig. 3). Northern Harbour belongs to the best class (very high) and the other regions are divided between very low (Gozo and Comino; Western; South Eastern) and low classes (Northern; Southern Harbour). SocIdeal shown in Fig. 4 is polarized. Two regions belong to the low classes (Northern) and very low (South Eastern), while the others belong to the high and even very high classes (Western). Global sustainability is represented in Fig. 4, showing the ranking of SustIdeal. For building the global index, EnvIdeal, SocIdeal and EcoIdeal have been considered equally important. All the regions belong at least to the medium class, except the South Eastern, due to the

Table 6

Alphanumeric indices.

\begin{tabular}{llll}
\hline \multirow{2}{*}{ Malta Regions } & \multicolumn{2}{l}{ Sustainability Indices } \\
\cline { 2 - 4 } & EnvIdeal & EcoIdeal & SocIdeal \\
\hline Gozo and Comino & 0.7463 & 0.2084 & 0.5249 \\
Northern & 0.5642 & 0.2987 & 0.4238 \\
Northern Harbour & 0.2235 & 0.8031 & 0.5415 \\
South Eastern & 0.5655 & 0.127 & 0.3799 \\
Southern Harbour & 0.4284 & 0.3577 & 0.5052 \\
Western & 0.6075 & 0.1921 & 0.582 \\
\hline
\end{tabular}

compensation effect among the three dimensions of sustainability.

Figs. 5-7 show three additional graphic outputs produced by GeoUmbriaSUIT. Each index produced is adimensional and scaled between $0 / 1$. Fig. 5 represents the chart of sustainability, in which the three indices are flanked. Therefore, it is clear how much each dimension is important in each region and there is no compensation at all. The higher the bar the better the performance of the relative dimension. In four regions the best dimension is the environmental one, while in the case of Northern Harbour region EcoIdeal is the best index. Southern Harbour is the only region with a small difference among the three dimensions and it is also the only one with SocIdeal as best index. Fig. 5 does not given a global ranking for the alternatives, since the three indices are not summed up. Fig. 7 reports the bars of sustainability: in this case the three dimensions are considered together and the result can be interpreted as a global ranking for sustainability. However in Fig. 7 you can see the relative importance of the three indices on the final ranking. The scale of Fig. 6 is not $0 / 1$ since it is the summation of the singular indices, but it is again an adimensional one, which can vary between 0 and 3, at most. For instance, the Northern Harbour clearly reaches the first position because of the good performance of EcoIdeal and SocIdeal, while EnvIdeal gives a very little contribution. On the other hand, Gozo and Comino is the second best region because EnvIdeal compensates for EcoIdeal. Fig. 8, the bubble graph, also allows evaluating the three dimensions at the same time. Information provided by Figs. 6 and 8 are very close but Fig. 8 could be even easier to read. For instance, it shows very clearly the Northern Harbour as being good from a social and economic point of view but unfortunately is bad from an environmental point of view. 


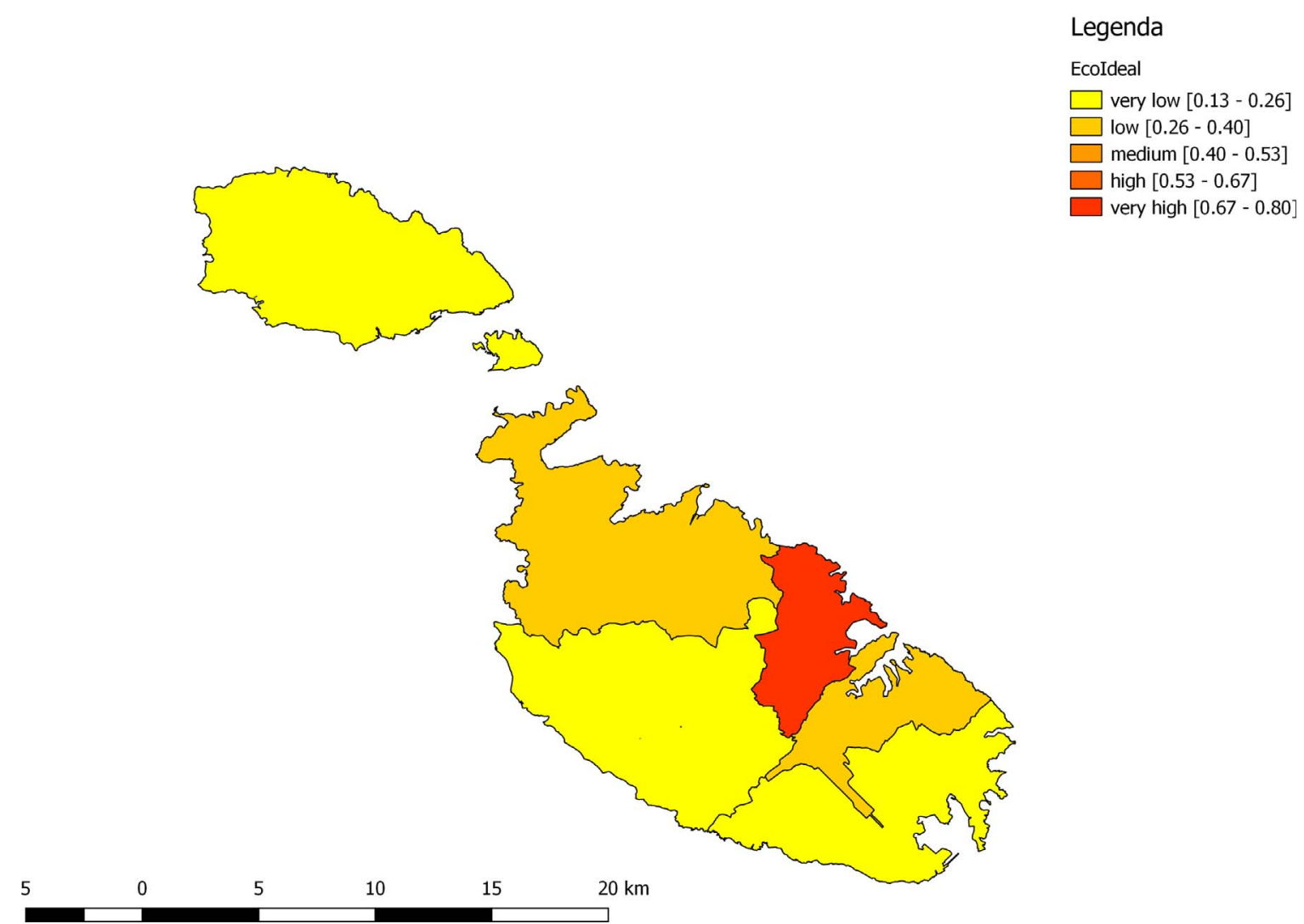

Fig. 2. EcoIdeal map.

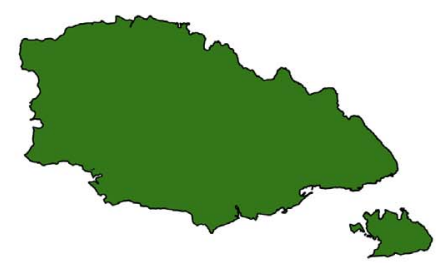

\section{Legenda}

EnvIdeal

$\square$ very low [0.22 - 0.33]

low $[0.33-0.43]$

$\square$ medium [0.43 - 0.54]

$\square$ high [0.54 - 0.64]

$\square$ very high [0.64 - 0.75]

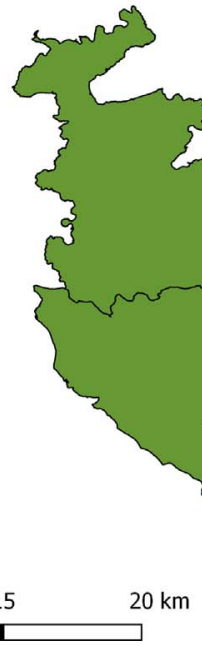

Fig. 3. EnvIdeal map. 


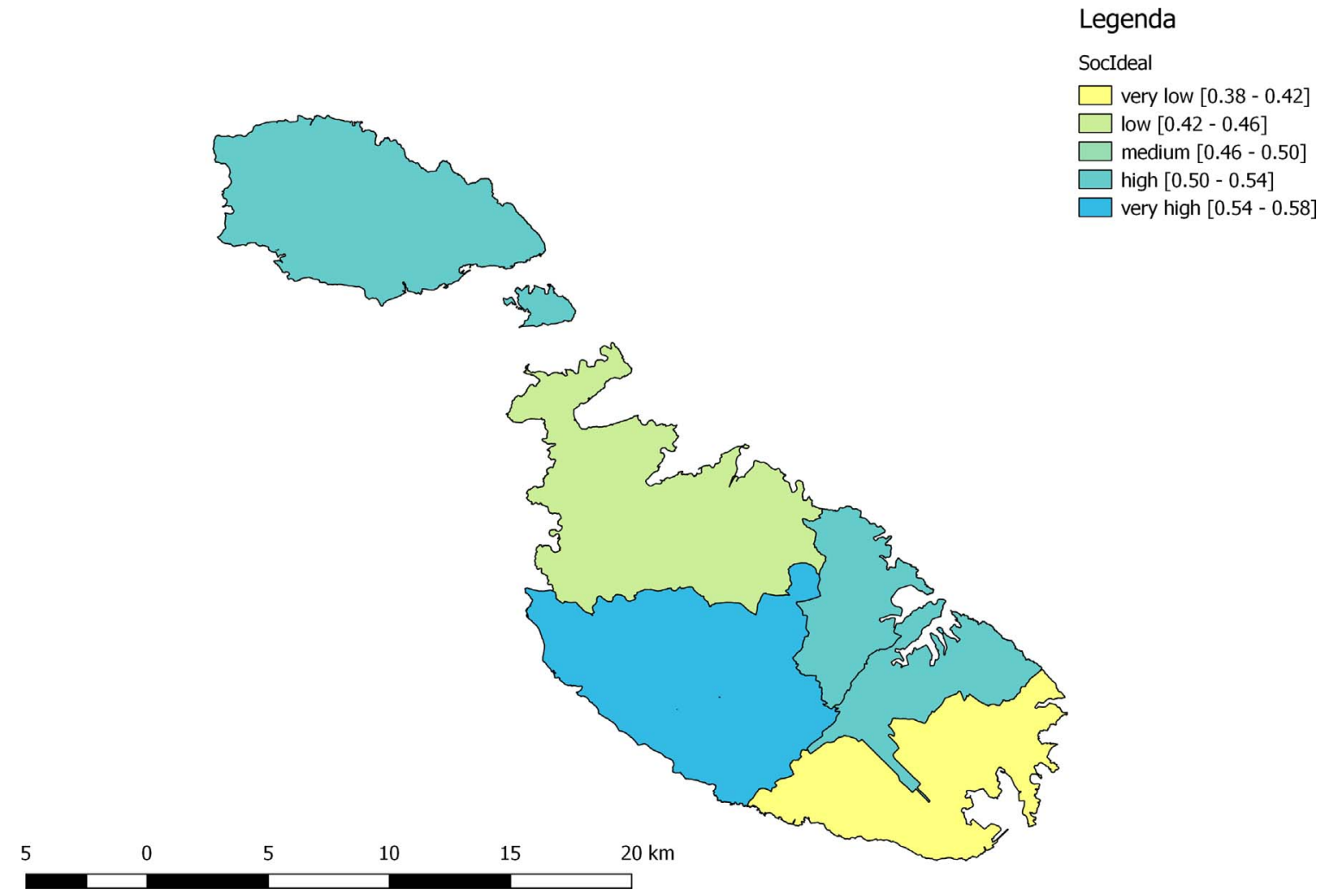

Fig. 4. SocIdeal map.

1.00 economic

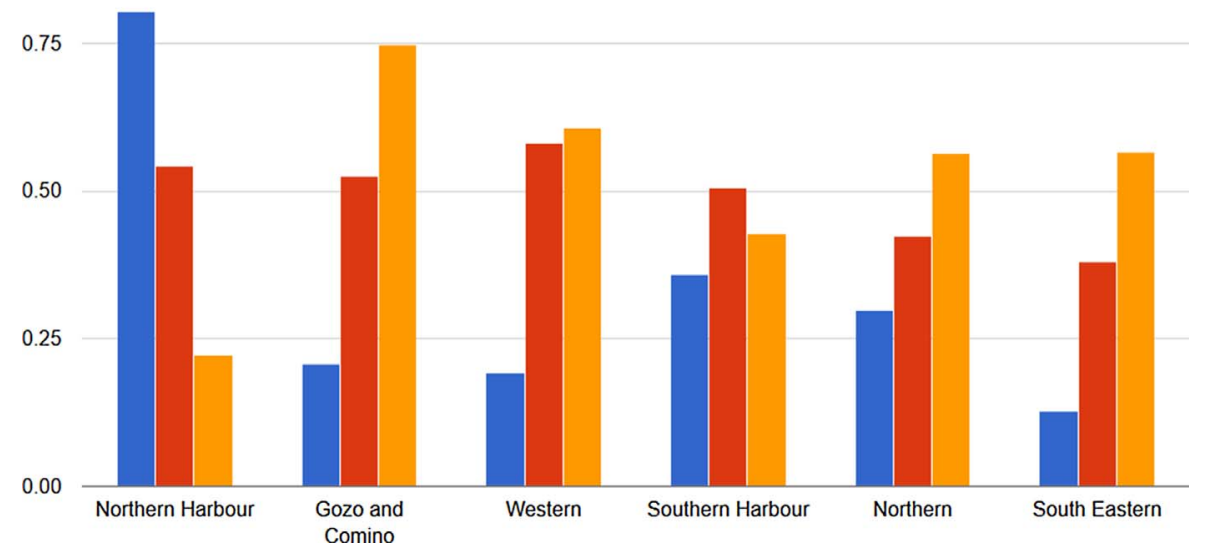

The outputs produced by GeoUmbriaSUIT are very informative and easy to understand by a decision maker. For instance, a decision maker looking at Fig. 8 should realize that regions could be divided into three different groups. Gozo and Comino and Western perform well from an environmental and social point of view; however they are not so good from an economic aspect. Southern East and Northern do not perform well from an economic and social point of view but they have good environmental scores. Finally, Southern Harbour and Northern Harbour are the two regions with the best performance of EcoIdeal, are also good according to SocIdeal but not to EnvIdeal. Such information is helpful for public decision makers to identify different regional needs, implement local politics, tailored on the local need highlighted by sustainability analysis. The possibility to maintain the three dimensions separate avoids the flattening of decision makers' interventions, because there is no compensation among them. Although it is possible to have a global sustainability index (SustIdeal) the decision maker is directly asked to balance the three components. Therefore (s)he is conscious about any compensation effects.

To better understand the compensation effect and the real meaning of SustIdeal, GeoUmbriaSUIT provides the possibility of performing a back analysis. It is possible to understand which dimension impacts more on the final result, trying to limit the above mentioned compensation effect. Therefore, although the weak approach to sustainability is applied, the decision maker can be also aware of the real meaning of the global index. Table 7 shows some of the rules extracted using the back analysis based on the DRSA. Decision rules can be defined as logical statement, very easy to understand since they are in the form of 'If... then...' sentences (Słowiński et al., 2009; Cinelli et al., 2015). In Table 7 , each rule is represented with the conditions that characterize it, the resulting decision class assignment, and the cases which support 
bars of sustainability

2.0

economic

social

environmental

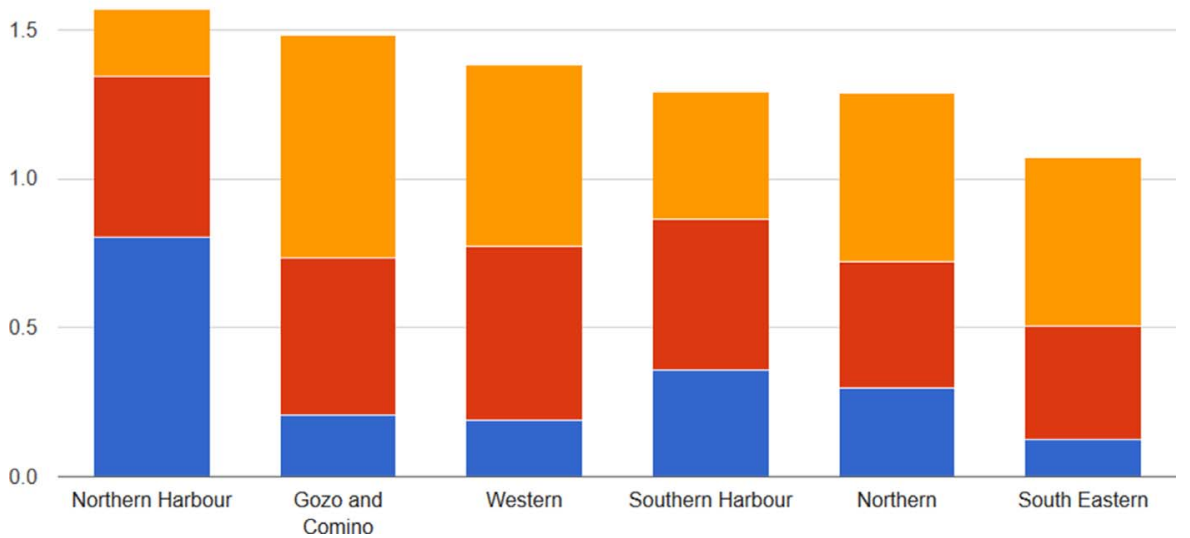

environment

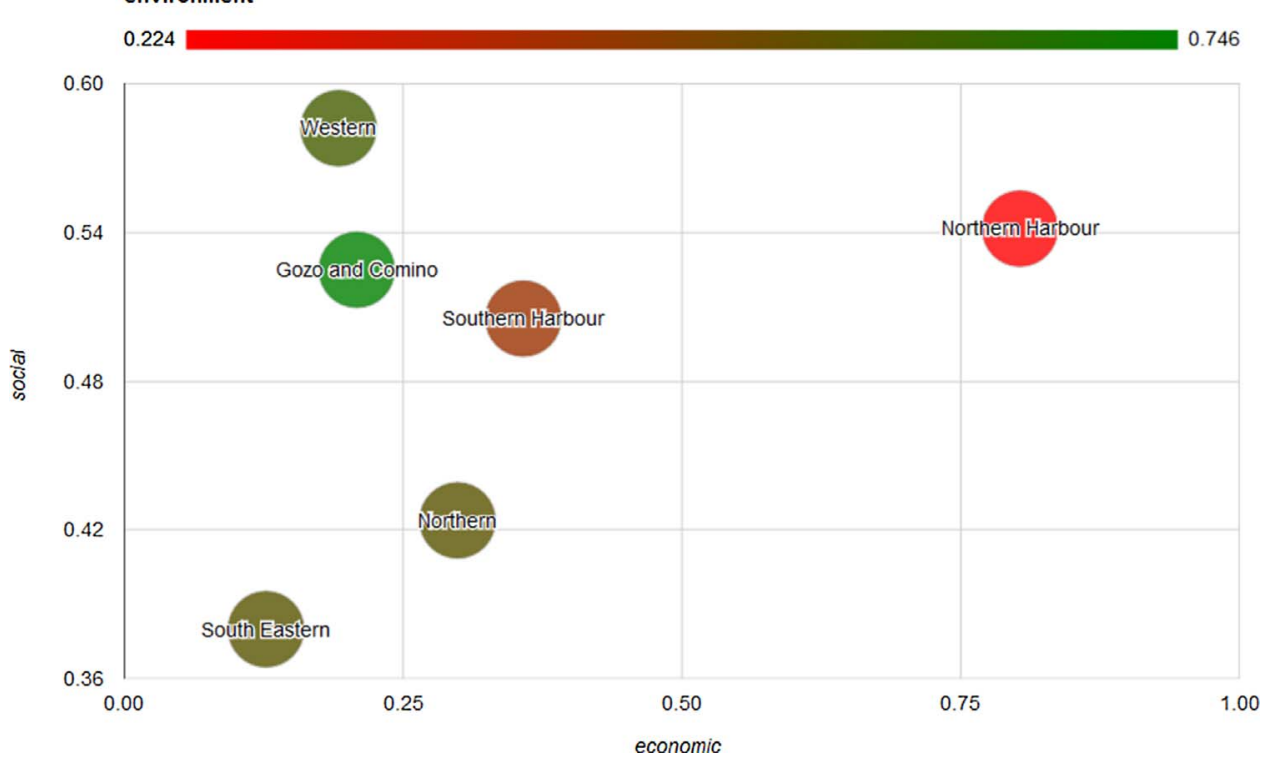

Fig. 6. Bar of sustainability.
Fig. 7. Bubble graph. it (Cinelli et al., 2015). Looking at our case study rules, it is clear that the social dimension has a great importance in determining the global result, probably because the environmental and economic dimensions are more polarized and they have an opposite behavior. In such a situation, SocIdeal is discriminating and the decision maker is aware of it because of this back analysis.

As the exemplary case showed, the presence of separate indices and graphic outputs make GeoUmbriaSUIT a readable and transparent tool, in comparison with other existing models that address sustainability assessment. Generally, classical models produce just an aggregate index of sustainability as final result of their calculations (see for example Kropp and Lein, 2012; Lombardi and Ferretti, 2015), which are often cryptic and difficult to interpret. The Dashboard of Sustainability, developed in the framework of the United Nations Commission on Sustainable Development (UNCSD) is an example of a model providing an overall index of sustainability, aggregating the information, and making the interpretation and the understanding of the results very difficult. As a matter of fact the Dashboard has been defined as a "black box". This is a typical problem that occurs when using evaluation tools for complex concepts such as sustainability, with outputs are represented in a single index. GeoUmbriaSUIT, on the contrary is easy to read, calculating three different indices for economic, environmental and social aspects, and providing several types of graphic outputs (maps, histograms and cartograms) in addition to the alphanumeric ones. Also in comparison to other MCDSS GeoUmbriaSUIT is easier and more flexible. Lopez and Monzon (2010), for instance, proposed a MCDSS which works with three different indices (Efficiency Score; Cohesion Score; Environmental Score). However, the outputs are limited and the type and number of indicators are also very few making it a fair tool for a limited type of analysis, mostly in the field of sustainable transport, for which it was built.

Differences in sustainability levels are directly influenced by the indicators that are chosen for the research. In order to analyze the results, one must understand and appreciate the chosen indicators. It is therefore important to highlight the use of a set of indicators to determine the levels of sustainable development in a region, rather than to base such descriptions on one or a few indicators. It is interesting to see how the indicators interact together and how these can all help to achieve the required sustainability levels. Thus, having a back analysis is another strength of GeoUmbriaSUIT. Thanks to the application of the Dominance Based Rough Sets Approach (DRSA), it allows the user to analyze each single step that leads to the final result, revealing which 


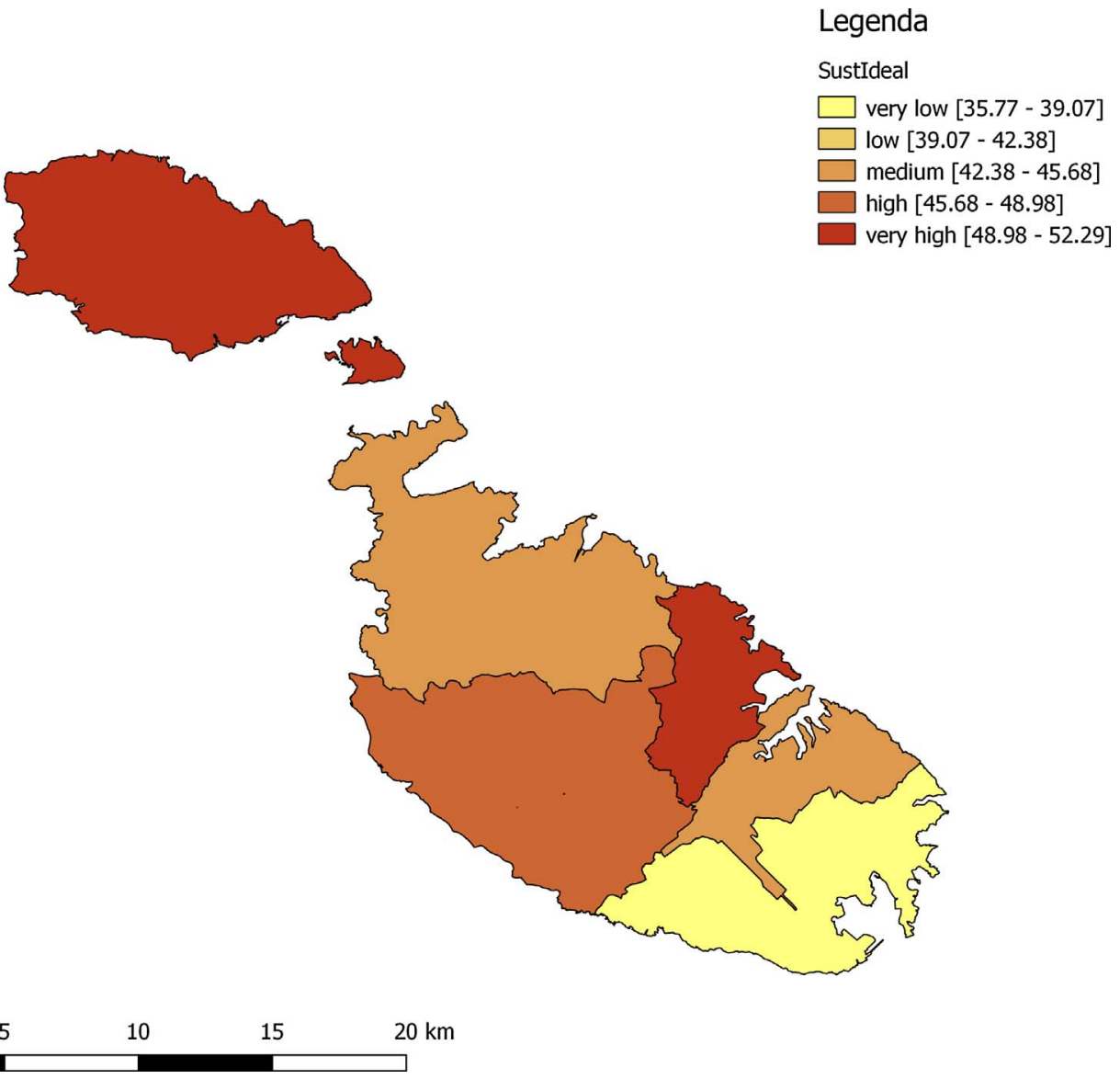

Fig. 8. SustIdeal Map.

Table 7

Back analysis.

\begin{tabular}{|c|c|c|c|c|c|}
\hline $\begin{array}{l}\text { Rule } \\
\text { number }\end{array}$ & & $\begin{array}{l}\text { Conditions } \\
\text { description }\end{array}$ & & Classification & Support Cases \\
\hline 1 & IF & S6 $<=41.3$ & AT MOST & very low & [4] \\
\hline 2 & & $\mathrm{~S} 6<=41.5$ & & medium & {$[2,4]$} \\
\hline 3 & & $\mathrm{~S} 4>=135.8$ & & medium & {$[5]$} \\
\hline 4 & & $S 6_{-}<=43.4$ & & high & {$[2,4,6]$} \\
\hline 5 & & $\mathrm{~S} 4>=135.8$ & & high & [5] \\
\hline 6 & & $S 6>=41.5$ & AT LEAST & medium & {$[1,2,3,5,6]$} \\
\hline 7 & & $\mathrm{~S} 3=418.0$ & & high & {$[1,6]$} \\
\hline 8 & & $\mathrm{~S} 5>=103616.0$ & & high & [3] \\
\hline 9 & & $\mathrm{~S} 5>=103616.0$ & & very high & [3] \\
\hline 10 & & $\mathrm{~S} 3<=367.0$ & & very high & [1] \\
\hline
\end{tabular}

indicators have the greatest impact on the results. This approach allows for a clear feedback organized in a learning oriented perspective, which permits to consider the procedure as a "glass box", contrary to the "black box" characteristic of many procedures giving final result without any clear explanation (Greco et al., 2008). Another advantage of GeoUmbriaSUIT is the absence of limits for criteria. A minimum or maximum number of criteria is not present and the user can chose all the indicators (s)he consider suitable for her/his analysis.

Definitely, the characteristics that all together make the model, in our opinion, efficient and rather innovative are the following:

- It is the first model to assess sustainability through MCSDSS by means of complete integration between MCDA and GIS. In general, partial forms of integration (explained above) are quite common, but the complete integration is still scarcely used.

- Because of the complete integration it is possible to use the results of the MCDA analysis for further geographical elaboration.

- The model was specifically projected for performing strategic sustainable planning and policy.

- It can be used at any territorial level (from local to supra-national).

- It deals both with the concepts of strong and weak sustainability. The user chooses which approach to apply.

- The interface is very simple, intuitive and guides the user in performing the analysis. This allows the model to run easily, even for not experts in GIS or MCDA.

- A back analysis through DRSA (Greco et al., 2001a) is integrated in the model, allowing for traceability, transparency and avoiding the concept of a model as a black box.

- The open source characteristics of the model (GNU GPL ver. 3 license) allow for open access to anyone interested in the model; everyone can download, use, and improve the model itself.

One of the major limitations of the current version of GeoUmbriaSUIT is the implementation of just one MCDA method. In a MCSDSS, the presence of more than a single algorithm is a big advantage, because it enables the use of the best method according to the problem at hand (Massei et al., 2014). However, the addition of new algorithms to GeoUmbriaSUIT is a further development envisaged for the model. Moreover, when using TOPSIS, the possibility of encountering the problem of rank reversal must be taken into account. García-Cascales and Lamata (2012) propose a modification of the method in an attempt to resolve this problem.

Another further development of GeoUmbriaSUIT is the possibility to handle multiple stakeholder preferences, directly inside the system. This can reduce the splitting bias in the weighting phase (Montibeller and Winterfeldt, 2015), which is one of the major issues of managing uncertainty in MCDA. Uncertainty is always present in decision making, 
therefore reducing it is a requirement for researchers (Fischhoff and Davis, 2014). This additional function would be of significant value to the GeoUmbriaSUIT model.

\section{Conclusions}

In this paper we presented our model for sustainability assessment based on the integration of Multi-Criteria Decision Analysis with Geographic Information Systems. This model helps the complex process of assessing the level of sustainability of a certain area. The model was demonstrated using a case study, the level of sustainability in Malta's six regions. Our results showed that the integration of MCDA-GIS is an adequate approach for sustainability assessment. Whilst MCDA is an established methodology for understanding complex issues, the use of GIS allows for results to be better understood by policy makers, who might not be experts and require understandable outputs. In addition, the evaluation path used in the proposed method is traceable and transparent. The model is also developed respecting the principle of strong sustainability, because three sets of indicators have been used, and they were separately considered for the economic, social and environmental assessment, in order to avoid compensation between the three dimensions of sustainability.

Sustainability studies allow decision makers to make informed decisions, be effective in terms of actions and policies, and apply the required focus on measures for sustainability. Understanding the different factors, social, environment and economic, affecting sustainability allows policy to identify areas and measures to be implemented where there is the most need. Integrated methodologies which allow the use of a number of indicators using a geographic approach improve the results of sustainability studies since the spatial focus allow for a better representation of actions according to the local, regional and national levels. This study has shown that, even within a small geographic area, spatial differences at regional levels identify the need for sustainability strategies which are not homogenous across a single territory at a national scale. The effectiveness of national policies which are widely applied through the territory depend on the regional characteristics. The proposed model identified specific needs in different areas.

Future research can include the testing of different multi-criteria methodologies integrated within GeoUmbriaSUIT. This would allow the study of properties and sensitivity and the identification of the most suitable methods for the use within the model. The presence of a wide range of methods enables the user to choose the best algorithm for each problem: the selection of the right one is still an open question in decision making.

Beside the good responses and the positive features underlined in the discussion section, this proposed model has a number of constraints, which are mainly related to the data and the choice of indicators. It became evident during the research that changes in indicators can have significant impacts on the results. However, in some cases this could even be seen as a positive issue. As a matter of fact, the model is not designed to be an automated data input-results output tool. It is a model to support policy makers in their decisions, coming from specific programs and political orientations. It means that decision makers can and have to choose the environmental, social and economic aspects to take into considerations in their analysis, thus the indicators. As a consequence, the indicators set can change, depending on the problem to solve.

\section{Acknowledgements}

This research is funded by ARPA Umbria, the Regional Agency for Environmental Protection, Region of Umbria, Italy.

\section{References}

support system prototype. Environ. Manage. 36 (2), 282-296.

Boggia, A., Cortina, C., 2010. Measuring sustainable development using a multi-criteria model: a case study. J. Environ. Manage. 91, 2301-2306.

Boggia, A., Pennacchi, F., Massei, G., Cortina, C., Marchetti, G., Stranieri, P., Caliò, R., Ricci, C., Bagagli, M., 2007. The Monitoring Model Software UmbriaSUIT 1.0. ARPA Umbria Press, Perugia (in Italian).

Boggia, A., Paolotti, L., Massei, G., Rocchi, L., Pace, E., Attard, M., 2016. A model to assess sustainability using multi-Criteria analysis and geographic information systems: a case study. In: Conference Proceedings of the 18th International Conference on Biosystems and Environmental Sciences. Buenos Aires, 27-28 ottobre 2016. WASET. ISSN: 2010-376X.

Bohringer, C., Jochem, P.E.P., 2007. Measuring the immeasurable - a survey of sustainability indices. Ecol. Econ. 63, 1-8.

Bond, A., Morrison-Saunders, A., Pope, J., 2012. Sustainability assessment: the state of the art. Impact Assess. Project Appraisal 30, 53-62.

Canavese, D., Diquera Ortega, N.R., Queiros, M., 2014. The assessment of local sustainability using the fuzzy logic: an expert opinion system to evaluate environmental sanitation in the Algarve Region Portugal. Ecol. Indic. 36, 711-718.

Chakhar, S., Martel, J.M., 2003. Enhancing geographical information systems capabilities with multi-criteria evaluation functions. J. Geogr. Inf. Decis. Anal. 7, 47-71.

Chakhar, S., Mousseau, V., 2007. An algebra for multicriteria spatial modelling. Comp. Environ. Urban Syst. 31, 572-596.

Cilia, G., 1995. Sustainable Development - Land Use in Malta Towards Sustainable Europe. Friends of the Earth (Malta), Malta.

Cinelli, M., Coles, S.R., Nadagouda, M.N., Błaszczyński, J., Słowiński, R., Varma, R.S., Kirwan, K., 2015. A green chemistry-based classification model for the synthesis of silver nanoparticles. Green Chem. 17, 2825-2839.

Cinelli, M., Coles, S.R., Kirwan, K., 2014. Analysis of the potentials of multi criteria decision analysis methods to conduct sustainability assessment. Ecol. Indic. 46, 138-148.

Cortina, C., Boggia, A., 2014. Development of policies for Natura 2000 sites: a multicriteria approach to support decision makers. J. Environ. Manage. 141, 138-145.

Dahl, A.L., 2012. Achievements and gaps in indicators for sustainability. Ecol. Indic. 17, 14-19.

European Environment Agency, 2006. Corine Land Cover 2006-Malta. Available from http://www.eea.europa.eu/data-and-maps/figures/corine-land-cover-2006-bycountry/malta (Accessed 2 March 2016).

Ekins, P., Simon, S., Deutsch, L., Folke, C., De Groot, R., 2003. A framework for the practical application of the concepts of critical natural capital and strong sustainability. Ecol. Econ. 44 (2-3), 165-185.

Ferretti, V., Pomarico, S., 2012. Integrated sustainability assessments: a spatial multicriteria evaluation for siting a waste incinerator plant in the Province of Torino (Italy). Environ. Dev. Sustain. 14 (5), 843-867.

Ferretti, V., Pomarico, S., 2013. An integrated approach for studying the land suitability for ecological corridors through spatial multicriteria evaluations Environment. Dev. Sustain. 15 (3), 859-885.

Fischhoff, B., Davis, A.L., 2014. Communicating scientific uncertainty. Proceedings of the National Academy of Sciences 111 13664-13671.

García-Cascales, M.S., Lamata, M.T., 2012. On rank reversal and TOPSIS method. Math Comput. Modell. 56, 123-132.

GIS Development Team, 2017. QGIS Geographic Information System Open Source Geospatial Foundation Project. http://www.qgis.org/.

Greco, S., Matarazzo, B., Slowinski, R., 2001a. Rough set theory for multi-criteria decision analysis. Eur. J. Oper. Res. 129, 1-47.

Greco, S., Matarazzo, B., Slowinski, B., Stefanowski, J., et al., 2001b. An algorithm for induction of decision rules consistent with the dominance principle. In: Tsumodo (Ed.), Rough Sets and Current Trends in Computing. Springer, pp. pp 304-313.

Greco, S., Matarazzo, B., Slowinski, B., Stefanowski, J., 2008. Dominance-Based rough set approach to interactive multi-objective optimization. In: Branke, J., Deb, K. Miettinen, K., Slowinski, R. (Eds.), Multi-objective Optimization: Interactive and Evolutionary Approaches. Springer-Verlag, Berlin.

Griggs, D., Stafford-Smith, M., Gaffney, O., Rockström, J.C., Öhman, M., Shyamsundar, P., Steffen, W., Glaser, G., Kanie, N., Noble, I., 2013. Policy: sustainable development goals for people and planet. Nature 495, 305-307.

Hwang, C.L., Yoon, K., 1981. Multiple Attribute Decision Making: Methods and Applications. Springer-Verlag, New York.

Kang, M.G., Lee, G.M., 2011. Multicriteria evaluation of water resources sustainability in the context of watershed management. J. Am. Water Resour. Assoc. 47 (4), 813-827.

Kropp, W.W., Lein, J.K., 2012. Assessing the geographic expression of urban sustainability: a scenario based approach incorporating spatial multicriteria decision analysis. Sustainability 4 (9), 2348-2365.

Laskar, A., 2003. Integrating GIS and Multi Criteria Decision Making Techniques for Land Resource Planning. International Institute for Aerospace survey and Earth Sciences (ITC), Enschede.

Liu, K., 2007. Evaluating environmental sustainability: an integration of multiple-criteria decision-making and fuzzy logic. Environ. Manage. 39 (5), 721-736.

Lombardi, P., Ferretti, V., 2015. New spatial decision support systems for sustainable urban and regional development. Smart Sustain. Built Environ. 4 (1), 45-66.

Lopez, E., Monzon, A., 2010. Integration of sustainability issues in strategic transportation planning: a multi-criteria model for the assessment of transport infrastructure plans. Comp. Aided Civ. Infrastruct. Eng. 25 (6), 440-451.

Malta Environment and Planning Authority, 2014. Source and Effects. Malta Environment and Planning Authority. Available at: https://www.mepa.org.mt/air-sources (Accessed 14 January 2014).

Malta Financial Services Authority, 2014. Companies Register. Available from http:// www.rocsupport.mfsa.com.mt (Accessed 2 March 2016). 
Macleod, C.J.A., Scholefield, D., Haygarth, P.M., 2007. Integration for sustainable catchment management. Sci. Total Environ. 373 (1-2), 591-602.

Malczewski, J., 2010. Multiple criteria decision analysis and geographic information systems. In: In: Ehrgott, M., Figueira, J., Greco, S. (Eds.), International Series in Operations Research \& Management Sciencevol 142. Springer, New York, pp. 369-395.

Malta Tourism Authority, 2014. Enforcement. Available at http://www.mta.com.mt/ enforcement (Accessed 6 January 2014).

Manos, B.D., Papathanasiou, J., Bournaris, T., Voudouris, K., 2010. A DSS for sustainable development and environmental protection of agricultural regions. Environ. Monit. Assess. 164 (1), 43-52.

Massei, G., Rocchi, L., Paolotti, L., Greco, S., Boggia, A., 2014. Decision support systems for environmental management: a case study on wastewater from agriculture. J. Environ. Manage. 146, 491-504.

Monmonmier, M., 1993. Mapping It Out: Expository Cartography for the Humanities and Social Sciences. University of Chicago Press.

Montefort, S., Lenicker, H.M., Caruana, S., Agius Muscat, H., 1997. Asthma and Other Allergenic Conditions in Childhood in the Maltese Islands. I.S.A.A.C. (Malta) Study, Malta.

Montibeller, G., Winterfeldt, D.V., 2015. Biases and Debiasing in Multi-criteria Decision Analysis. 48th Hawaii International Conference on System Sciences (pp.1218-1226), 5-8 Jan. 2015. 1218-1226.

Munda, G., 2005. Multi-criteria decision analysis and sustainable development, in Figueira. In: Figueira, J., Greco, S., Ehrgott, M. (Eds.), Multiple Criteria Decision Analysis: State of the Art Surveys. Springer, New York, pp. 953-986.

National Statistics Office, 2011. World Water Day 2011 News Release 054/2011. National Statistics Office, Malta. Available from http://nso.gov.mt/en/News Releases/ Archived_News_Releases/Documents/2011/News2011_054.pdf.

National Statistics Office, 2012. Malta Census of Housing and Population 2011 Preliminary Report. National Statistics Office. Available from https://nso.gov.mt/en/ publicatons/Publications_by_Unit/Documents/01_Methodology_and_Research/ Census2011_PreliminaryReport.pdf.

National Statistics Office, 2013a. Social Security Benefits: A Locality Perspective 2013. National Statistics Office. Available from https://nso.gov.mt/en/publicatons/ Publications_by_Unit/Documents/A2_Public_Finance/Social_Security_Benefits_2013. pdf.

National Statistics Office, 2013b. Statistics on Income and Living Conditions: SILC 2011 News Release 112/2013. National Statistics Office. Available from https://nso.gov. mt/en/News_Releases/Archived_News_Releases/Documents/2013/News2013_112. pdf.

National Commission for Sustainable Development, 2006. A Sustainable Development Strategy for Malta. National Commission for Sustainable Development, Government of Malta, Malta.

Ness, B., Urbel Piirsalu, E., Anderberg, S., Olsson, L., 2007. Categorising tools FOS sustainability assessment. Ecol. Econ. 60, 498-508.

Ottomano Palmisano, G., Govindan, K., De Boni, A., Roma, R., 2015. Multicriteria spatial decision support systems for assessing sustainability in rural parks: an application of geo umbria suit model. In: 27th European Conference on Operational Research. EURO 2015 Glasgow Conference Handbook - Technical Program. Glasgow, July $12-15$.

Ottomano Palmisano, G., Govindan, K., Bogria, A., Loisi, R.V., De Boni, A., Roma, R., 2016a. Local Action Groups and Rural Sustainable Development. A spatial multiple criteria approach for efficient territorial planning. Land Use Policy 59, 12-26.

Ottomano Palmisano, G., Loisi, R.V., Ruggiero, G., Rocchi, L., Boggia, A., Dal Sasso, P., 2016b. Using analytic network process and dominance-based rough set approach for sustainable requalification of traditional farm buildings in southern Italy. Land Use Policy 59, 95-110.

Pace, A., 2012. Analysing Education and Health Indicators and Malta's Urban
Development Densities Using GIS. Unpublished MSc Dissertation. Institute for Climate Change and Sustainable Development, University of Malta, Malta.

Pace, E., 2014. Analysis of Sustainable Development in Malta Using a Multi-Criteria Model. Unpublished MSc Dissertation. Institute for Climate Change and Sustainable Development, University of Malta, Malta.

Paolotti, L., Massei, G., Rocchi, L., Stranieri, P., Caliò, R., Ricci, C., Boggia, A., 2015. A new tool for sustainability assessment in geographic environment: geoUmbriaSUIT. In: 27th European Conference on Operational Research. EURO 2015 Glasgow Conference Handbook - Technical Program. Glasgow, J uly 12-15 2015.

Paolotti, L., Boggia, A., Agullo Torres, A.M., Del Campo Gomis, F.J., 2016. The model GeoUmbriaSUIT for territorial sustainability assessment: an application to Italian and Spanish case studies. In: 28th European Conference on Operational Research. EURO 2016 Poznan Conference Handbook - Technical Program. Poznan (Polonia), 3-6 luglio 2016.

Planning Services Division, 1992. Structure Plan for the Maltese Islands. Government of Malta. Available from www.pa.org.mt (Accessed 14 November 2016.

Pollesch, N.L., Dale, V.H., 2016. Normalization in sustainability assessment: methods and implications. Ecol. Econ. 130, 195-208.

Prato, T., Herath, G., 2007. Multiple-criteria decision analysis for integrated catchment management. Ecol. Econ. 63 (1-2), 627-632.

Ravetz, J., 2000. Integrated assessment for sustainability appraisal in cities and regions. Environ. Impact Assess. Rev. 20 (1), 31-64.

Rocchi, L., Massei, G., Paolotti, L., Boggia, A., 2015. Sustainable planning in small areas: a multicriteria approach. In: 23rd International Conference on Multiple Criteria Decision Making MCDM 2015-Bridging Disciplines. Book of. Hamburg, 2015 Hamburg, August 2-7 2015.

Rowley, H.V., Peters, G.M., Lundie, S., Moore, S.J., 2012. Aggregating sustainability indicators: beyond the weighted sum. J. Environ. Manage. 111, 24-33.

Saaty, R.W., 1987. The analytic hierarchy process- what it is and how it is used. Math Model. 9 (3-5), 161-176.

Sala, S., Farioli, F., Zamagni, A., 2013. Progress in sustainability science: lessons learnt from current methodologies for sustainability assessment: part 1. Int. J. Life Cycle Assess. 18, 1653-1672.

Sala, S., Ciuffo, B., Nijkamp, P., 2015. A systemic framework for sustainability assessment. Ecol. Econ. 119, 314-325.

Sheppard, S.R.J., 2005. Participatory decision support for sustainable forest management: a framework for planning with local communities at the landscape level in Canada. Can. J. For. Res. 35 (7), 1515-1526.

Shmelev, S.E., Labajos-Rodrigues, B., 2009. Dynamic multicriteria assessment of macro sustainability: case study of Austria. Ecol. Econ. 68 (10), 2560-2573.

Singh, R.K.S., Murty, H.R., Gupta, S.K., Dikshit, A.K., 2012. An overview of sustainability assessment methodologies. Ecol. Indic. 15 (1), 281-299.

Słowiński, R., Greco, S., Matarazzo, B., 2009. Rough sets in decision making. In: Meyers, A.R. (Ed.), Encyclopedia of Complexity and Systems Science. Springer, New York, New York, NY.

Store, R., 2009. Sustainable locating of different forest uses. Land Use Policy 26 (3) 610-618.

Transport Malta, National Household Travel Survey 2010, Transport Malta, 2011. http:// www.transport.gov.mt/admin/uploads/media-library/files/NHTS2010\%20Report. pdf_20120502091559.pdf (Accessed 23 November 2017).

United Nations Conference on Trade And Development, 2015. Investment Policy Framework For Sustainable Developmen. United Nations UNCTAD/WEB/DIAE/PCB/ 2015/3.

Waas, T., Hugé, J., Block, T., Wright, T., Benitez-Capistros, F., Verbruggen, A., 2014. Sustainability assessment and indicators: tools in a decision-making strategy for sustainable development. Sustainability 6, 5512-5534.

White, D., Fennessy, S., 2005. Modeling the suitability of wetland restoration potential at the watershed scale. Ecol. Eng. 24 (4), 359-377. 